\title{
When sex meets syntactic gender on a neural basis during pronoun processing
}

Citation for published version (APA):

Hammer, A., Goebel, R. W., Schwarzbach, J. V., Münte, T. F., \& Schmitt, B. M. (2007). When sex meets syntactic gender on a neural basis during pronoun processing. Brain Research, 1146, 185-198. https://doi.org/10.1016/j.brainres.2006.06.110

Document status and date:

Published: 01/01/2007

DOI:

10.1016/j.brainres.2006.06.110

Document Version:

Publisher's PDF, also known as Version of record

Document license:

Taverne

Please check the document version of this publication:

- A submitted manuscript is the version of the article upon submission and before peer-review. There can be important differences between the submitted version and the official published version of record.

People interested in the research are advised to contact the author for the final version of the publication, or visit the DOI to the publisher's website.

- The final author version and the galley proof are versions of the publication after peer review.

- The final published version features the final layout of the paper including the volume, issue and page numbers.

Link to publication

\footnotetext{
General rights rights.

- You may freely distribute the URL identifying the publication in the public portal. please follow below link for the End User Agreement:

www.umlib.nl/taverne-license

Take down policy

If you believe that this document breaches copyright please contact us at:

repository@maastrichtuniversity.nl

providing details and we will investigate your claim.
}

Copyright and moral rights for the publications made accessible in the public portal are retained by the authors and/or other copyright owners and it is a condition of accessing publications that users recognise and abide by the legal requirements associated with these

- Users may download and print one copy of any publication from the public portal for the purpose of private study or research.

- You may not further distribute the material or use it for any profit-making activity or commercial gain

If the publication is distributed under the terms of Article $25 \mathrm{fa}$ of the Dutch Copyright Act, indicated by the "Taverne" license above, 


\title{
Research Report
}

\section{When sex meets syntactic gender on a neural basis during pronoun processing}

\author{
Anke Hammer ${ }^{a, c, *}$, Rainer Goebel ${ }^{a, b}$, Jens Schwarzbach ${ }^{a, b}$, \\ Thomas F. Münte ${ }^{c}$, Bernadette M. Jansma ${ }^{a}$ \\ ${ }^{a}$ Faculty of Psychology, Department of Neurocognition, Maastricht University, Maastricht, The Netherlands \\ ${ }^{b}$ F.C. Donders Centre for Cognitive Neuroimaging, Nijmegen, The Netherlands \\ ${ }^{\mathrm{c} D e p a r t m e n t}$ of Neuropsychology, Otto-von-Guericke-Universität Magdeburg, Germany
}

\section{A R T I C L E I N F O}

Article history:

Accepted 28 June 2006

Available online 10 August 2006

Keywords:

Language

Pronoun processing

Syntax

Semantic

fMRI

\begin{abstract}
A B S T R A C T
We used event-related functional magnetic resonance imaging (erfMRI) to investigate the neural basis of biological and syntactic gender integration during pronoun processing in German sentences about persons or things. German allows for separating both processes experimentally. Overall, syntactic processing activated areas adjacent to Broca's area (BA 44), whereas processing of the biological sex, in addition, involved the supramarginal gyrus (BA 39). A previously reported event-related potential study using identical material suggests that syntactic and semantic information is integrated 400-700 ms after target onset, visible in both cases as a P600 but with different effect sizes. The fMRI and ERP results illuminate that pronoun processing involves a highly dynamic spatiotemporal integration of syntactic and biological information depending on the type of the antecedent and whether or not a violation is involved. The results are discussed in the context of cognitive models of pronoun processing.
\end{abstract}

C 2006 Elsevier B.V. All rights reserved.

\section{Introduction}

Reading emails, newspapers, letters of friends or books is one of our daily businesses. Usually, we are not aware of the details of this cognitive task because it goes on in a largely automatic fashion. Among other things, in order to understand a message, we have to integrate the meaning and the syntactic relations of single words. For example, in "The woman is happy, because she is in love" the pronoun "she" refers back to the antecedent "woman" in terms of meaning and syntax. Thus, pronouns are sophisticated language devices that allow a speaker to refer to an earlier mentioned person or thing. In order to establish this reference, pronouns have to match the conceptual meaning (biological gender), if available, and the syntax of the noun (syntactic gender). In the German language, for example, "the woman" ('die Frau') has a female biological gender with a corresponding feminine syntactic gender, which becomes apparent in the article "die". ${ }^{1}$ However, "the jacket" ('die Jacke') has just an arbitrary feminine syntactic gender with no semantic gender reflex. These properties make the German language well suited to investigate the contribution of semantic and syntactic information to pronoun processing because one can disentangle their respective contribution experimentally.

\footnotetext{
${ }^{1}$ The masculine gender article (nominative form) is "der", the neuter gender article "das".

* Corresponding author. Department of Neuropsychology, FNW/Institute of Psychology, Otto-von-Guericke-Universität Magdeburg, PostBox 4120, 39016 Magdeburg, Germany. Fax: +49 3916711947.

E-mail address: eadanke.hammer@nat.uni-magdeburg.de/ead (A. Hammer).
} 
Garrod and Sanford (1994) presented a cognitive model with two stages for pronoun interpretation (see also Garrod and Terras, 2000) with (1) a bonding stage, which is an automatic, more syntax-related process associated with establishing a link between the pronoun and a previous expression, and (2) a resolution or integration stage, which is testing and resolving this link. The integration is responsible for evaluating the established link, i.e., by weighting syntactic and semantic discourse information. In case of congruency, the integration process finishes with a so-called commitment. In case of incongruency, the integration process fails or is delayed. Possibly the search goes on for a suitable antecedent outside the current sentence (Hammer et al., 2005). As a pronoun is a linguistic device, which refers back to an earlier mentioned item, memory recourses might play an important role because the pronoun has to be matched with a distant antecedent. Van Berkum and colleagues (2003) showed increased demands on memory for discourse-referential ambiguity (e.g., "the girl" with two girls introduced in discourse context).

So far, pronoun processing has been investigated with reaction time and event-related brain potentials (ERPs). ERPs offer the advantage of a high temporal resolution. Moreover, a number of different effects have been described that show a relative specificity for semantic (the "N400" component, for example, Kutas and Hillyard, 1980) and syntactic processes (the "P600/SPS", e.g., Hagoort et al., 1993; Osterhout and Holcomb, 1992; for a review, see Hagoort et al., 1999), even though the specificity - in particular of the P600 - has been questioned by several sets of data (Kolk et al., 2003; Münte et al., 1998; van Herten et al., 2005). ERP investigations of pronoun processing have yielded conflicting results. For example, when pronouns violated stereotypical gender (e.g., surgeon = male), both a P600 (Osterhout et al., 1997) or an N400 (Kutas et al., 2000) have been reported. One reason for the variety of results might be that ERP signals depend on the type of antecedent (i.e., diminutives, persons, or things) as has been shown by our group (Hammer et al., 2005; Schmitt et al., 2002). Furthermore, as mentioned above, memory resources might be involved (e.g., van Berkum et al., 2003). That means that at least three types of cognitive processes are relevant during pronoun processing that might modulate the ERP components of interest; i.e., syntactic information, semantic/biological information and memory resources.

In a preceding ERP study using the same material as here, Hammer et al. (2005) reported such a P600 modulation during pronoun processing at the critical word, i.e., pronouns referring back to either person antecedent (biological and syntactic gender information) or thing antecedent (pure syntactic gender information). Incongruent (gender) conditions were associated with a typical P600 effect that was larger for person compared to thing conditions. The larger P600 in the person condition was interpreted to reflect a failure of integration of both biological/semantic and syntactic gender information, whereas the smaller P600 in the thing condition reflects integration of syntactic gender information proper. In addition, we reported an N400 on the word following the pronoun but only in sentences about things. We suggested that "making sense out of a sentence" during pronoun resolution is not a rule-based process but rather dynamic, i.e., it depends on the type of antecedent (person or thing).
Thus, a complex picture emerges based on electrophysiological studies suggesting that brain potentials alone are probably not sufficient to distinguish the relative contribution of semantic and syntactic processes to the resolution of pronouns. The aim of the current study was to localize brain regions related to pronoun integration and to compare the functional specificity of brain areas with the temporal information of the ERP results with regard to semantic and syntactic processing.

Syntactic processing has traditionally been linked to the left inferior frontal gyrus (GFi), as patients with lesions in Broca's area are characterized by agrammatic speech. Broca's area in the posterior part of the left GFi exhibits two general anatomical subdivisions referred to as pars triangularis (Brodmann's areas (BA) 45) and pars opercularis (BA 44) (Tomaiuolo et al., 1999). Brain imaging studies of grammatical processing have shown that BA 44 is sensitive to the grammatical complexity of sentences (Caplan et al., 1998; Fiebach et al., 2001; Stromswold et al., 1996). Posterior-inferior portion of BA 44 has been related to syntactic structure building processes (Friederici et al., 2003; Röder et al., 2002).

Interestingly, semantic processing seems to engage similar but also different areas. For example, Kiehl and colleagues (2002) used a typical violation paradigm, in which they presented semantic violations ("The dog caught the ball in his mouth vs. soup"). Incongruent compared to congruent sentences revealed increased activity in a widespread network including bilateral frontal regions and temporal regions. A recent study by Hagoort et al. (2004) investigated semantic and general world knowledge violations in an fMRI experiment and reported common activations of brain area BA 45 but also 47, which were more active compared to correct sentences.

Of particular interest for the present investigation are studies comparing semantic and syntactic violations in the same experiment. Kuperberg et al. (2003) presented correct/ semantically incongruent/syntactically incongruent sentences (e.g., "We could not sleep at night because the baby would cry/remember/cries.") in a rapid event-related fMRI study. Relative to correct sentences, semantic violations were associated with an increased activity in left temporal and inferior frontal areas and a decreased response in the right medial parietal cortex. Syntactic violations on the other hand were associated with an increased response in bilateral medial and lateral parietal regions and a decreased response in left temporal and inferior frontal regions. This suggests that the two types of violations can be processed in different ways (decrease vs. increase of neural activity) albeit by the same neural systems. Friederici et al. (2003) auditorily presented correct ("The shirt was ironed."), semantically incorrect ("The thunderstorm was ironed.") and syntactically incorrect ("The blouse was on ironed.") sentences. Whereas semantic violations activated the mid-portion of the superior temporal region and the insular cortex bilaterally, syntactic violations revealed stronger activation of the anterior portion of the left superior temporal gyrus and a region adjacent to Broca's area.

To our knowledge, so far only one fMRI study addressed pronoun processing before. Grewe and colleagues (2005) addressed the role of the GFi in language-specific linearization of hierarchical linguistic dependencies. Most important for the 
current study, the comparison between pronominal and nonpronominal sentences did not reveal a different activation pattern in GFi. Assuming that GFi indeed reflects syntactic processing, the similar activation in GFi for nouns and pronouns indicates comparable syntactic processing for both types of stimuli. The semantic aspect of pronoun processing has not been addressed.

The present event-related fMRI study aims at directly disentangling semantic and syntactic contributions to pronoun processing by systematically varying the type of violation, which is possible in German because of its rich gender system. German subjects read sentences, in which an antecedent was either a person or a thing. This antecedent was introduced in the first phrase. In the second phrase, a pronoun was presented, which either referred back to the antecedent in the first phrase (congruent pronoun), or which was incongruent with the antecedent. The underlying rational was that the incongruency leads to a syntactic violation in the thing conditions, as a thing has a syntactic but no biological gender. The incongruency in the person condition leads to a double violation, as both syntactic and biological gender were violated. Example sentences are given in the material section.

Given the variety of brain activations for syntactic and semantic processes found in fMRI studies on sentence comprehension and the lack of preceding pronoun fMRI data, we only formulated tentative hypotheses: Pure syntactic violations compared to congruent sentences (i.e., thing sentences) were expected to lead to a modulation of activity in left inferior frontal regions (Friederici et al., 2003; Indefrey et al., 2001; Kuperberg et al., 2003) and temporal regions (Friederici et al., 2003; Kuperberg et al., 2003). A combination of syntactic and biological/semantic sentences compared to congruent sentences (i.e., person sentences) were expected to modulate activity in the same/adjacent frontal regions (Friederici et al., 2003; Hagoort et al., 2004; Kuperberg et al., 2003; Martin and Chao, 2001) and additionally in parietal regions (Kuperberg et al., 2003). In case we find a more complex pattern for person compared to thing sentences, this might illuminate the sources for the different P600 effects found in the preceding ERP experiment.

\section{Results}

\subsection{All sentences against fixation}

Comparing all sentences against fixation using a random effects GLM analysis revealed a bilateral network, which appeared to be more extended on the left hemisphere (Fig. 1, Panel A). This network is associated with language processing (left lateralized temporal-frontal regions) as well as more general processes associated with stimulus perception (occipital and motor cortex). The corresponding beta-weights for all four predictors estimated by ROI-based GLM analyses are displayed in Fig. 1, Panel B. Detailed information of ROIs is listed in Table 1. Most ROIs revealed an increased activation for incongruent pronouns compared to congruent pronouns (Panel B). A comparison within the person condition (congruent vs. incongruent; double violation) revealed a significant difference in activation in the left inferior frontal gyrus pars triangularis (GFi t), left inferior frontal gyrus pars opercularis (GFi op), anterior part of left superior temporal gyrus (STs II) and the right GFi (Table 1, person contrast). A comparison within the thing conditions (congruent vs. incongruent; syntactic violation) showed a significant difference within right GFi t, GFi op, superior parietal lobule (LPs), posterior STs (STs II-IV), superior temporal sulcus (GTs) and the right GFi (Table 1, thing contrast). A comparison between the congruent conditions (congruent person vs. congruent thing) revealed differences within left STs and parts of the right pre- and postcentral gyri (Table 1, congruency contrast).

In order to examine regional specificity and spatial extent of differential activation between pronoun types, we performed direct comparisons for person and thing pronouns, which are reported below.

\subsection{Effects of violations}

For the person condition (Fig. 2, Panel A), the incongruent sentences elicited a larger BOLD response than congruent sentences in two areas on both hemispheres, namely the inferior frontal gyrus (GFi, BA 44) and the supramarginal/ angular gyrus (Gsm/Ga, BA 39/40) as well as portions of the left medial frontal gyrus (GFm, BA 6). Averaged event-related time courses of the BOLD response (Fig. 3, Panel A) showed a prominent increased activation for incongruent persons compared to congruent persons in bilateral GFi and GFm, whereas for bilateral Gsm/Ga a rather decreased activation of the congruent person condition and a late increased activation was found for the incongruent condition. The corresponding beta weights are shown for group (Fig. 4, Panel A1) and individual comparisons (Fig. 4, Panel A2).

For the thing condition (Fig. 2, Panel B), the incongruent sentences led to a larger signal change than congruent sentences in three areas all located in the left hemisphere, namely the GFi (BA 44), the GFm (BA 6) and the STs (BA 21) but no significant activation in the right hemisphere. Averaged event-related time courses (Fig. 3, Panel B) showed an increased BOLD response for incongruent compared to congruent sentences all three areas (see beta weights in Fig. 4, Panel B). These areas, except the GFm, are the same brain regions that have been reported before for semantic and syntactic integration.

A visual inspection of the time courses revealed shifts in the BOLD maxima across incongruent conditions and ROIs (see Fig. 5). The time course for the incongruent person showed an early maximum of the BOLD signal change in the left GFi, followed by a maximum in the left GFm, and later in the left Gsm/Ga. Performing direct comparisons of the timeto-peak interval calculated from trial-averaged time courses of region of interest for each subject revealed that GFi was activated before GFm (7.7 vs. $10.7 \mathrm{~s}$ after onset of the critical pronoun; $t_{10}$; two-tailed $\left.=4.5, p<0.005\right)$, and GFm before Gsm $/ \mathrm{Ga}$ (10.7 vs. $12.3 \mathrm{~s}$; $t_{10}$; two-tailed $=2.8, p<0.05$ ).

For the incongruent thing conditions, first the left GFi and STs reacted maximally to the violation followed by the left GFm. Here, time-to-peak did not differ between GFi (8.3 s) and STs (9.1 s; $t_{10}$; two-tailed $=1.4$, not significant). GFm (10.5 s) showed a later time-to-peak than GFi ( $t_{10}$; two-tailed $\left.=3.9, p<0.005\right)$, and 
A
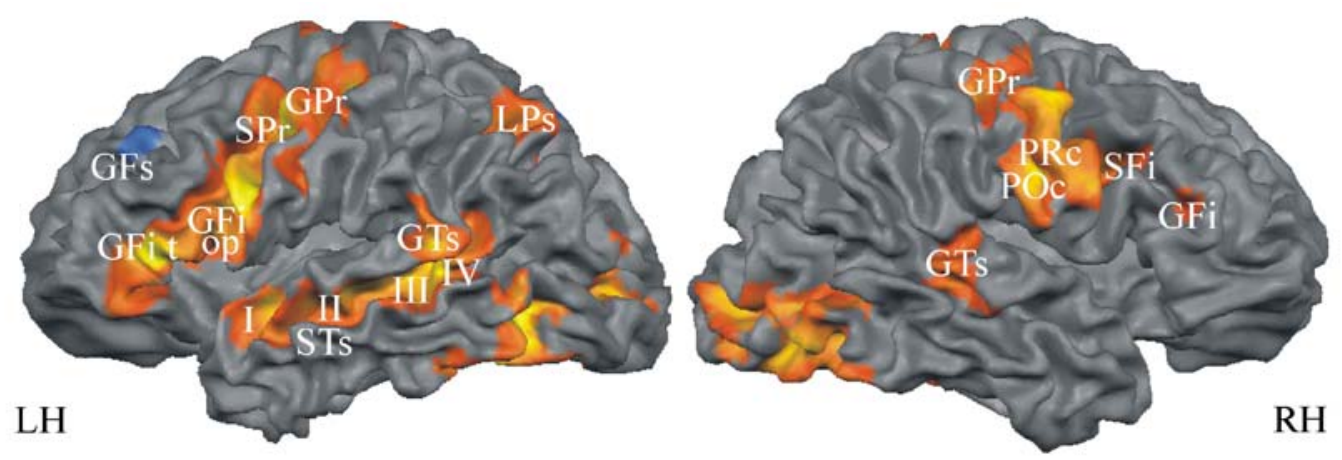

B

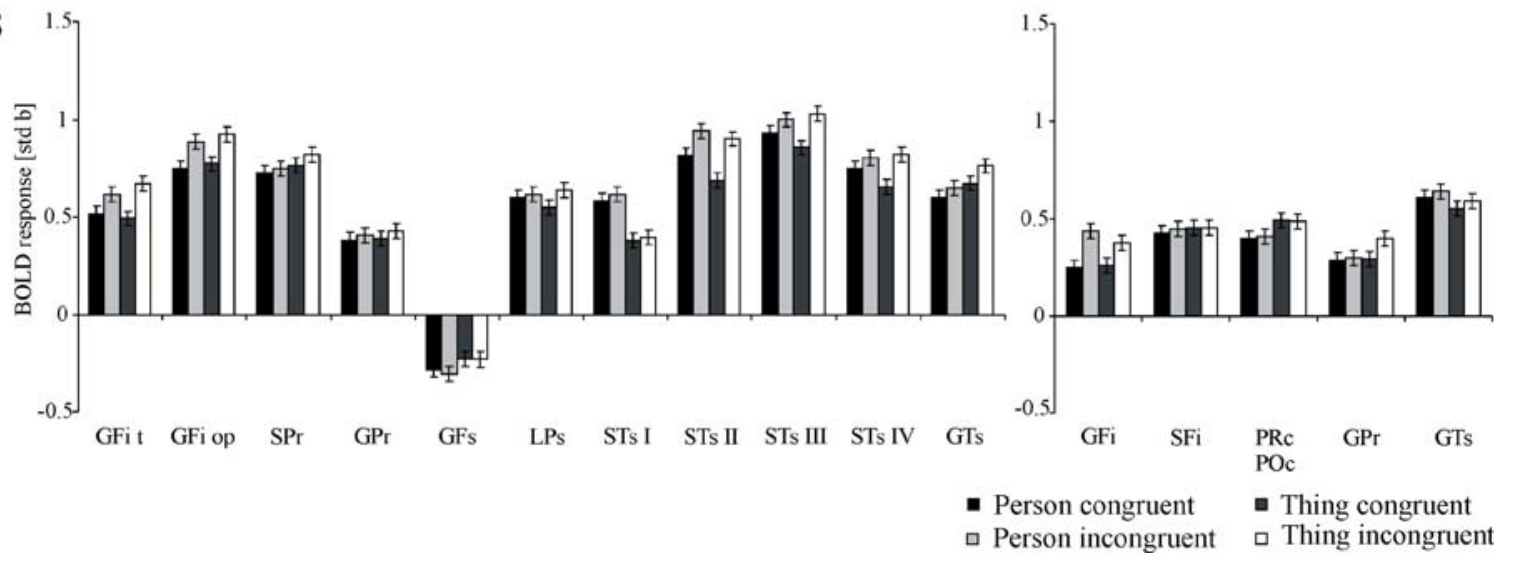

Fig. 1 - (A) Activated voxels as revealed by across participant ( $n=11$ ) analysis (random effects full model GLM) after cortex-based inter-subject spherical alignment based on gyral/sulcal patterns of individual brains. For detailed ROI information, see Table 1. (B) Standardized $b$ weights ( $\beta$ estimates) for all four predictors are shown for each respective ROI. Error bars indicate SEM across subjects. Abbreviations: LH: left hemisphere; RH right hemisphere; GFi: inferior frontal gyrus; GFit: inferior frontal gyrus pars triangularis; GFiop: inferior frontal gyrus pars opercularis; SFs: superior frontal sulcus; GFs: superior frontal gyrus; STs: superior frontal gyrus; Gsm: supramarginal gyrus; GTs: superior temporal gyrus; LPs: superior parietal lobule; SPr: precentral sulcus; GPr: precentral gyrus; PRc: precentral; POc: postcentral.

GFm showed a tendency to be later than STs ( $t_{10}$; twotailed $=2.1, p<0.06)$.

\subsection{Comparison of congruent person and thing conditions}

In order to directly asses the contribution of semantic and syntactic information to building up co-reference, we compared the congruent person and thing conditions. This direct comparison of the two congruent conditions revealed several areas that were more active for the thing condition, i.e., the condition that allowed co-referencing solely on the basis of syntactic information (Fig. 2, Panel C). These areas were the bilateral Gsm/Ga and the left GFi. The respective event-related time courses for these areas (Fig. 3, Panel C) show that for these areas indeed congruent thing sentences featured an increased activation compared to congruent person sentences. On the other hand, the person condition, which allowed co-referencing to be based on biological/semantic and syntactic information, gave rise to increased activation in two regions, the anterior part of the left STs (BA 22) and the most posterior portion of the same structure (BA 37/21). This contrast is also visible in the event-related time courses, which attest an increased activation for congruent person compared to congruent thing sentences in temporal regions.

\section{Discussion}

The aim of the study was to assess the contribution of syntactic and biological/semantic gender information during pronoun processing and to link it to ERP findings using the identical material. As in our previous study with ERPs (Hammer et al., 2005), we found robust differences for sentences with person antecedents compared to sentences with thing antecedents underscoring that indeed it makes a difference whether co-referencing has to be based solely on syntactic information (syntactic gender of a thing) or can potentially draw on conceptual information as well (biological sex in addition to syntactic gender of a person). The present design allowed two ways of analysis: Firstly, the effects of violations in the person and thing conditions could be compared. Secondly, the brain activations for the correct sentences of both conditions were contrasted.

Overall activation of integrating a pronoun into a sentence (all sentences compared to baseline) revealed a bilateral widespread cortical network, which was more pronounced on the left hemisphere. Most importantly, the different pronoun types showed differential activation within these regions reflected in differential beta weights. In order to 
Table 1 - ROI details for full model

\begin{tabular}{|c|c|c|c|c|c|c|c|c|}
\hline & \multicolumn{3}{|c|}{ Talairach } & \multirow{2}{*}{$\frac{\text { Size }}{\text { Voxel }}$} & \multicolumn{3}{|c|}{ Contrast } & \multirow[t]{2}{*}{$\mathrm{BA}$} \\
\hline & $x$ & $y$ & $z$ & & Person & Thing & Congruency & \\
\hline \multicolumn{9}{|l|}{$\mathrm{LH}$} \\
\hline GFi t & -39 & 29 & 9 & 1894 & $2.3 ;<0.02$ & $4.1 ; 0.00004$ & 0.5 & 45 \\
\hline GFi op & -46 & 15 & 24 & 2435 & $3.2 ; 0.001$ & $3.6 ; 0.0004$ & -0.5 & 44 \\
\hline $\mathrm{SPr}$ & -45 & -3 & 40 & 3314 & 0.5 & 1.26 & -0.9 & 6 \\
\hline GPr & -37 & -16 & 53 & 2182 & 0.6 & 0.9 & -0.2 & 4 \\
\hline GFs & -26 & 35 & 40 & 115 & -0.5 & -0.1 & -1.3 & 9 \\
\hline LPs & -28 & -60 & 46 & 1087 & 0.8 & $2.6 ; 0.008$ & 1.3 & 7 \\
\hline STs I & -50 & 2 & -4 & 994 & 0.8 & 0.4 & $4.7 ; 0.000003$ & 38 \\
\hline STs II & -50 & -17 & 0 & 1269 & $3.1 ; 0.002$ & $4.9 ; 0.000001$ & $2.9 ; 0.004$ & $22 / 21 ?$ \\
\hline STs III & -49 & -32 & 4 & 1538 & 1.6 & $4.1 ; 0.00005$ & $1.8 ; 0.07$ & 21 \\
\hline STs IV & -46 & -44 & 13 & 1664 & 1.3 & $3.8 ; 0.0001$ & $2.3 ; 0.03$ & 21 \\
\hline GTs & -56 & -37 & 18 & 1050 & 1.2 & $2.0 ; 0.04$ & $-17 ; 0.08$ & 42 \\
\hline \multicolumn{9}{|l|}{$\mathrm{RH}$} \\
\hline GFi & 46 & 27 & 23 & 102 & $4.4 ; 0.00001$ & $2.7 ; 0.006$ & -0.2 & 45 \\
\hline SFi & 40 & 6 & 32 & 881 & 0.4 & 0.1 & -0.6 & $6(44)$ \\
\hline $\mathrm{PRc} / \mathrm{POc}$ & 53 & -6 & 36 & 3227 & 0.2 & -0.3 & $-2.3 ; 0.02$ & 4 \\
\hline GPr & 41 & -22 & 49 & 2878 & 0.1 & $2.3 ; 0.02$ & 0.1 & 3 \\
\hline GTs & 54 & -28 & 6 & 1934 & 0.8 & 0.9 & 1.2 & 22 \\
\hline \multicolumn{9}{|c|}{$\begin{array}{l}\text { Talairach coordinates }(x, y, z) \text {, cluster size (number of activated voxels), statistical values (t; } p \text { ) for person (incongruent minus congruent), thing } \\
\text { (incongruent minus congruent), congruency (person minus thing) and presumed Brodmann's areas (BA) of regions for a full model (all predictors } \\
\text { against fixation) in left (LH) and right (RH) hemisphere based on group statistics of the ROIs revealed by individual cortex-based alignment. GFi: } \\
\text { inferior frontal gyrus; GFit: inferior frontal gyrus pars triangularis; GFiop: inferior frontal gyrus pars opercularis; SFs: superior frontal sulcus; GFs: } \\
\text { superior frontal gyrus; STs: superior frontal gyrus; Gsm: supramarginal gyrus; GTs: superior temporal gyrus; LPs: superior parietal lobule; SPr: } \\
\text { precentral sulcus; GPr: precentral gyrus; PRc: precentral, POc: postcentral. }\end{array}$} \\
\hline
\end{tabular}

examine the regional specificity and spatial extent of the different sentences, we performed direct comparisons. The direct comparisons revealed networks that highly overlapped with the overall activation but also differed to some extent as different activations related to single conditions might cancel each other out.

Violations in the person condition showed bilateral activation of the inferior frontal gyrus (GFi), the left medial frontal gyrus (GFm) and the bilateral supramarginal/angular gyrus (Gsm/Ga) compared to congruent person sentences (Figs. 1A and $2 \mathrm{~A}$ ). Violations in the thing conditions were associated with a more restricted pattern of activations including the left GFi/GFm and left superior temporal sulcus (STs) (Figs. 1B and 2B). Overall, these data suggest that pronoun processing is not strictly rule based but that it undergoes dynamic context depended changes in neural circuits. One such context is the type of the antecedent for a particular pronoun (person or thing). As expected from our working hypothesis, the violation in the thing condition showed a constraint activation pattern at the left hemisphere, whereas a violation in the person condition recruits a more complex network bi-laterally. This seems plausible as the person condition involves a double violation (i.e., semantic/conceptual and syntactic gender information) whereas the thing condition does involve a syntactic violation only. The double violation led to a higher amount of integration effort, reflected in the observed more complex activation.

Processing differences are also apparent in the direct comparison of the two congruent conditions (Figs. 2C and 3C). Please note that this comparison avoids the potential difficulties associated with rather general attention processing in violation paradigms (see Coulson et al., 1998, for a discussion related to ERP). In this comparison, the anterior part of the left GFi and the Gsm/Ga of both hemispheres were more active in the thing condition. In turn, two left temporal areas (BA 22, BA $37 / 21$ ) showed a stronger activation in the person condition. We will now consider these areas in light of the available imaging literature.

\subsection{Frontal areas}

The present experiment led to bilateral incongruency effects in the inferior frontal area for the person condition but only to left-hemispheric effects for the thing condition. The person condition allows co-referencing on both semantic and syntactic grounds. Kiehl et al. (2002) obtained similar bilateral inferior frontal activations in an experiment using semantic violations, thus suggesting that the right inferior frontal cortex might be specialized in the attempt to integrate the pronoun on the basis of conceptual/semantic information, whereas left inferior frontal activation appears to be related to the syntactic computations common to the thing and person conditions. The recruitment of right inferior frontal regions for semantic information processing was also shown during deductive reasoning (Goel et al., 2000), semantic vs. syntactic anomalies (Kang et al., 1999), metaphor processing (Bottini et al., 1994; Mashal et al., 2005) and topic maintenance compared to logic judgment (Caplan and Dapretto, 2001) (for an overview on right hemispheric activation, see Bookheimer, 2002). In our case, attempting to integrate incongruent person-pronouns seems to result in a right lateralization as the activation of the right GFi is larger than the left (see Fig. 2, Panel A, and amount of activated voxels reported in Table 2). This right lateralization is 
A
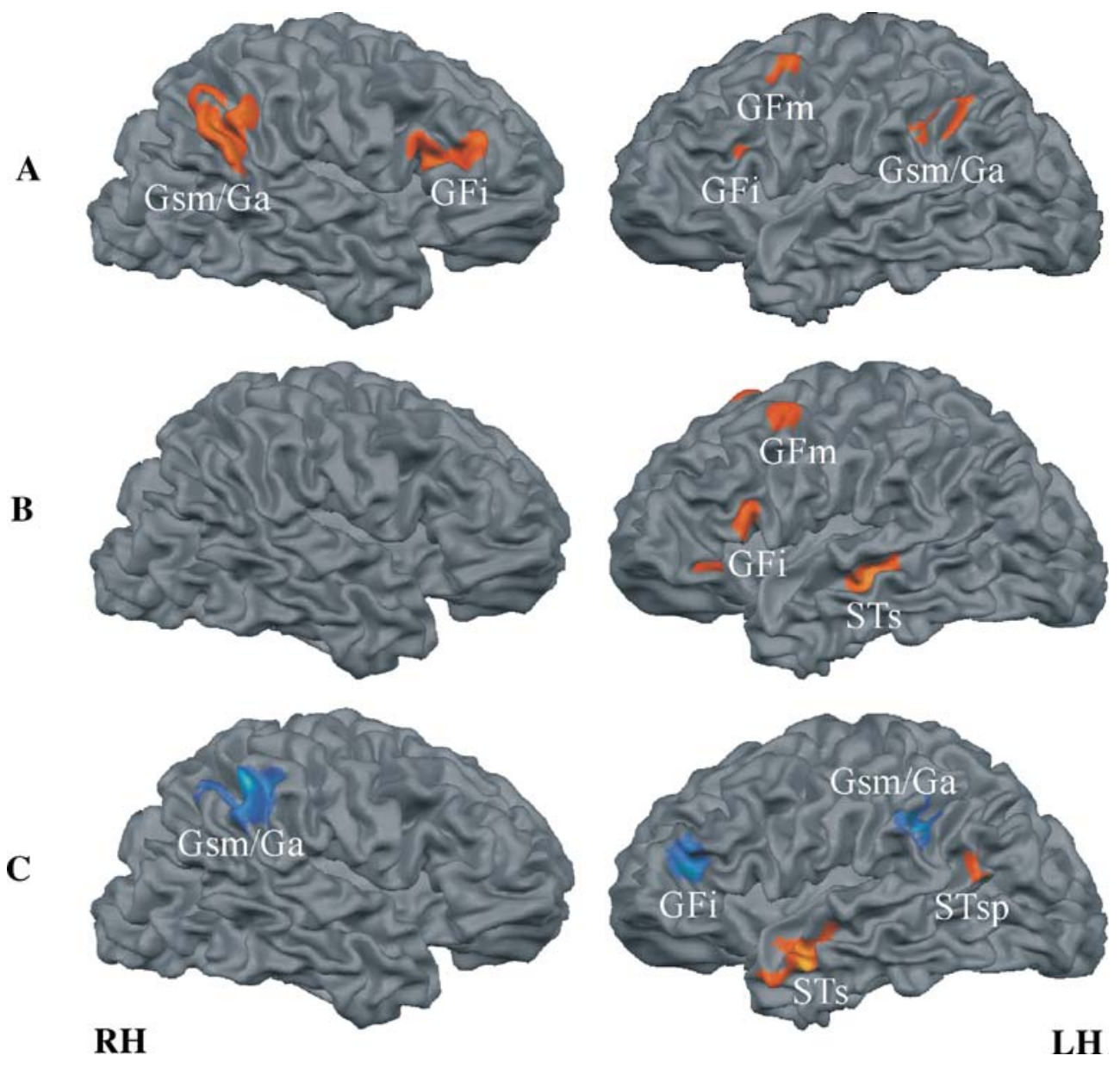

Fig. 2 - Activated voxels as revealed by across participant $(n=11)$ analysis (GLM) after cortex-based inter-subject spherical alignment based on gyral/sulcal patterns of individual brains. For detailed Talairach space information and Brodmann's areas (BA), see Table 2. (A) Person: Incongruent minus congruent person sentences. ROI: left and right GFi, left and right Gsm/Ga and GFm. For event-related time courses, see Fig. 3, Panel A, and for beta-weights see Fig. 4, Panel A. (B) Thing: Incongruent minus congruent thing sentences. ROI: left GFi, left GFm and left STs. For event-related time courses see Fig. 3, Panel B, and for beta-weights see Fig. 4, Panel B. (C) Congruency: Congruent person minus congruent thing sentences. Red=more positive activity to congruent person than to congruent thing sentences. Blue=more positive activity to congruent thing than to congruent person sentence. ROI: left GFi, left and right Gsm/Ga, left STs, left STsp. For event-related time courses see Fig. 3, Panel C, and for beta-weights see Fig. 4, Panel C. Abbreviations: LH: left hemisphere; RH: right hemisphere; GFi: inferior frontal gyrus; Gsm: supramarginal gyrus; Ga: angular gyrus; GFm: medial frontal gyrus; STs: superior temporal sulcus; STsp: posterior superior temporal sulcus.

eventually due to an increased integration effort during processing of a double-violated pronoun, as it is not observed in single syntactic violations (thing condition).

The comparison of congruent sentences revealed an increased activity in GFi for thing sentences compared to person sentences indicating that the integration of thing sentences demands more processing activity compared to person sentences. We conclude that the establishment of coreference in congruent sentences using only one gender information (syntactic) is more difficult than the integration of two available types of gender information (biological and syntactic) as the availability of two types of gender information might increase the strength of the linkage between pronoun and antecedent. There is consensus in earlier research using self-paced reading studies and eye tracking that the resolution process can be facilitated by additional information (Arnold et al., 2000; Garnham et al., 1995; Gernsbacher and Shroyer, 1989). In the present case, this would be the additional presence of biological/semantic gender information next to syntax.

An area activated by incongruent pronouns in the thing and the person condition was the left medial frontal gyrus (GFm, BA 6). This area has been commonly associated with working memory processes (e.g., Awh et al., 1995; Jonides et al., 1993, 1998; LaBar et al., 1999; Schumacher et al., 1996). In a review, Cabeza and Nyberg (2000) reported reliable activation of GFm for verbal and spatial tasks that require the active maintenance of abstract representations, but no reliable activation for tasks involving iconic stimuli (e.g., objects, faces). We propose that the activation of this area in the present study relates to the need to retrieve additional contextual information from working memory in incongruent 

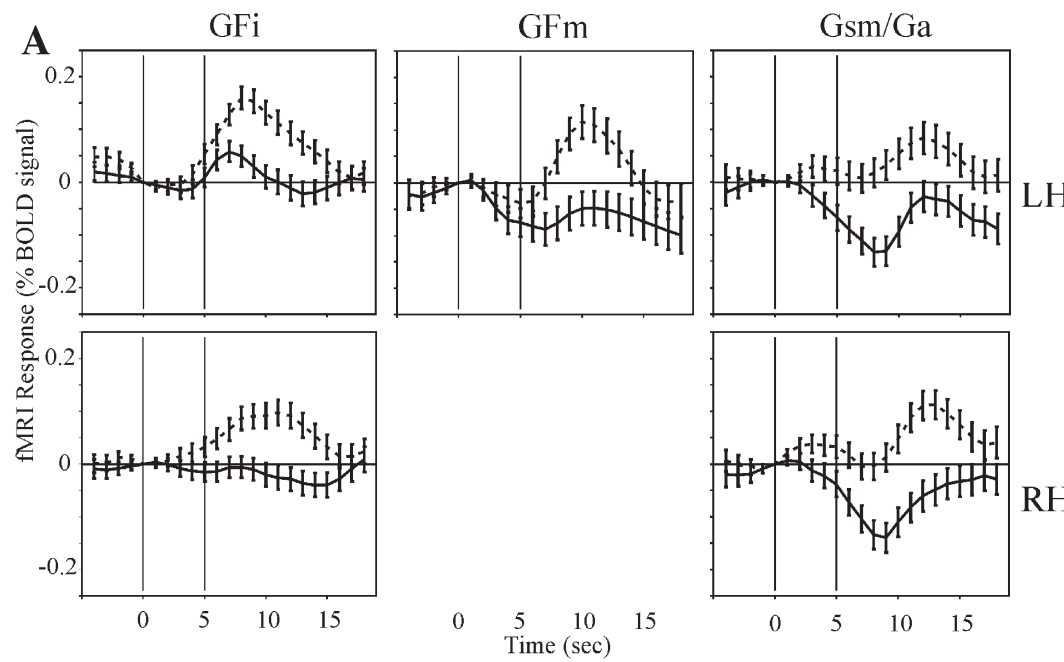

LH
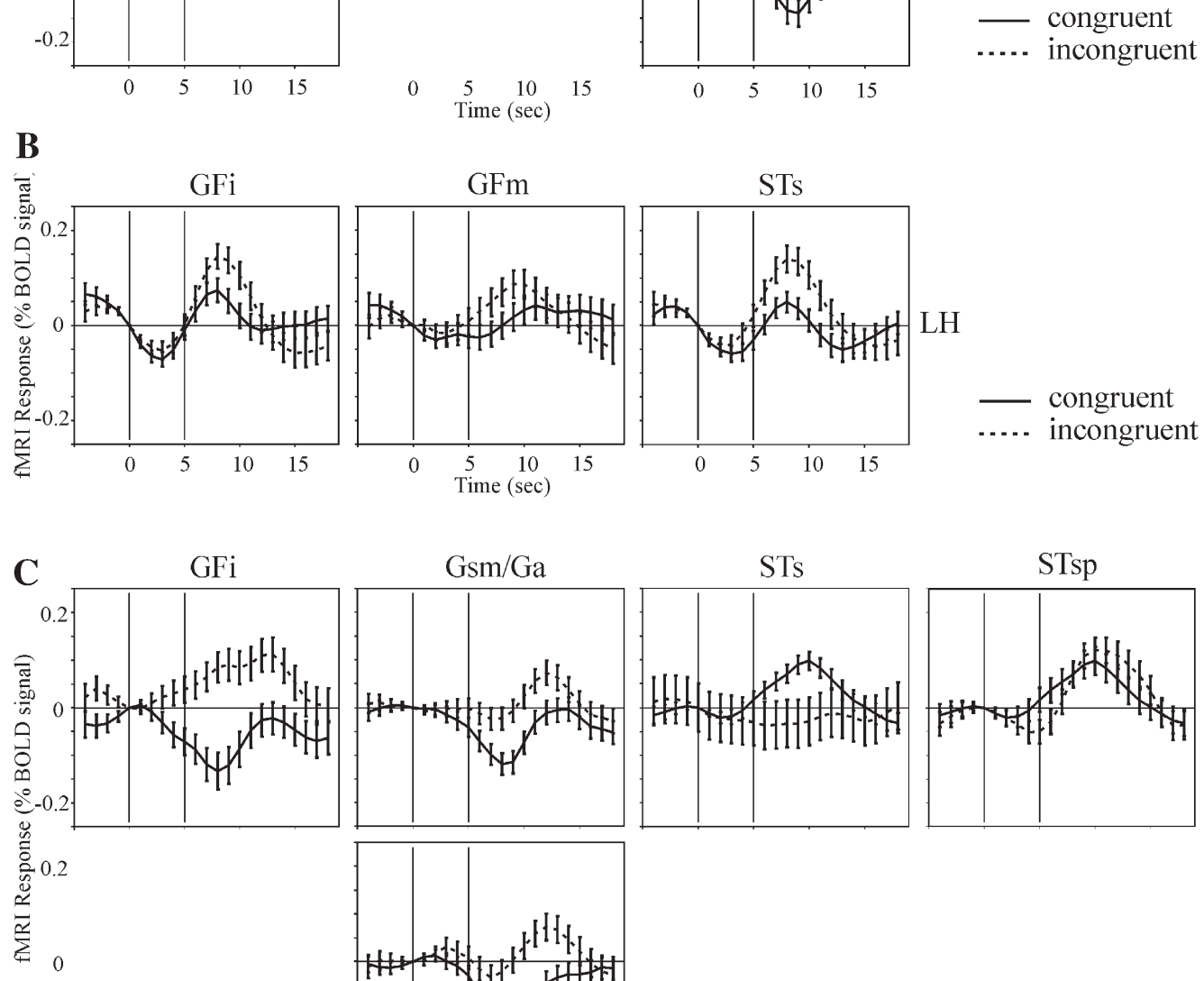

LH

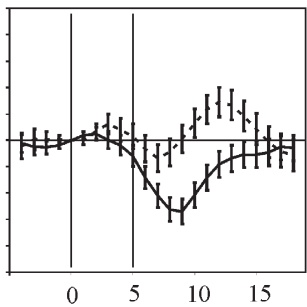

...... incongruent

$-0.2$

$\begin{array}{llll}0 & 5 & 10 & 15\end{array}$

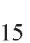

Fig. 3 - Event-related average time course of the BOLD response are shown for the respective regions of interest (ROI) for person sentences (Panel A), thing sentences (Panel B, solid lines represent congruent sentences and dotted lines represent incongruent sentences) and congruent sentences (Panel C, solid lines represent person sentences and dotted lines represent thing sentences).

sentences. As the incongruent pronoun enters the comprehension system, it lacks an antecedent within sentence context and therefore increased working memory resources are needed to access possible abstract or long distance (out of sentence) context information. This is not true for congruent person or thing pronouns as building up co-reference between a congruent pronoun and its presumed antecedent is a fast and nearly automatic process (first stage of pronoun processing; Garrod and Sanford, 1994). With the given data, it is not possible to conclude that no memory resources are needed for congruent pronoun processing - it is rather highly expected but there is an increased demand on memory resources in case of violation as there might be the attempt to integrate the incongruent pronoun via alternative contextual information. The involvement of working memory in referential relations has been reported earlier in theoretical assumptions (for an account of referentially induced working memory load, see Gibson, 1998) and by an ERP study of discourse processing (van 
GROUP

A1

LH

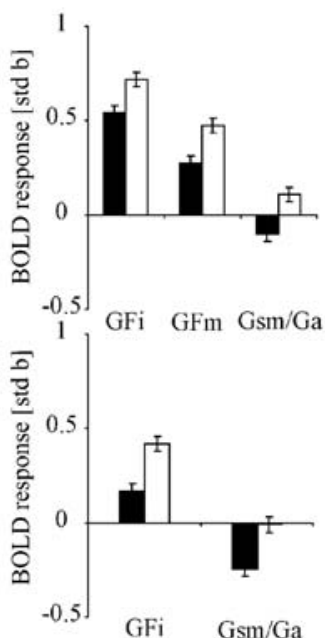

PERSON

SINGLE SUBJECTS

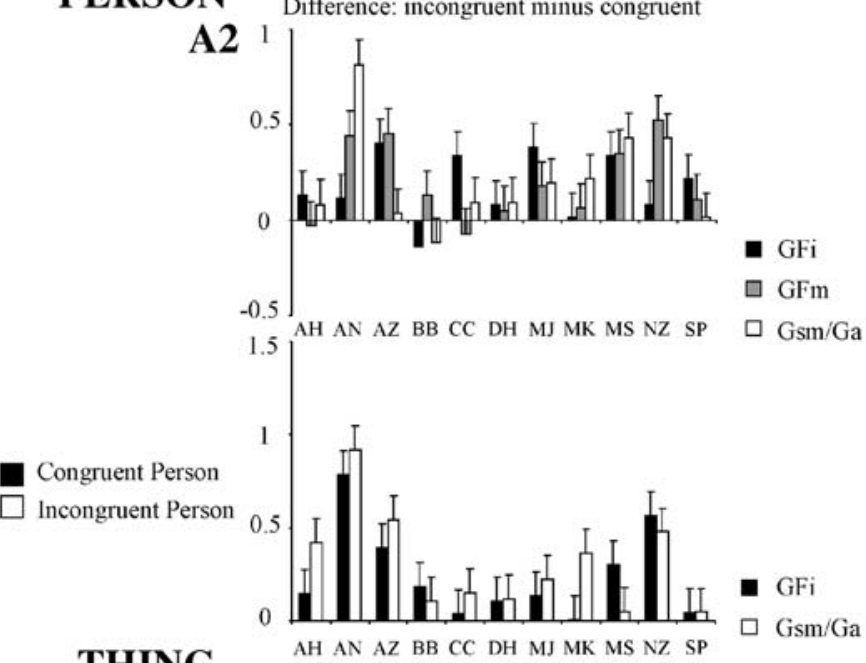

THING

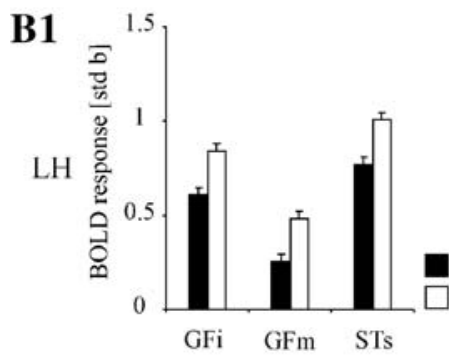

B2 1

Congruent Thing

Incongruent Thing -0.5

\section{CONGRUENCY}
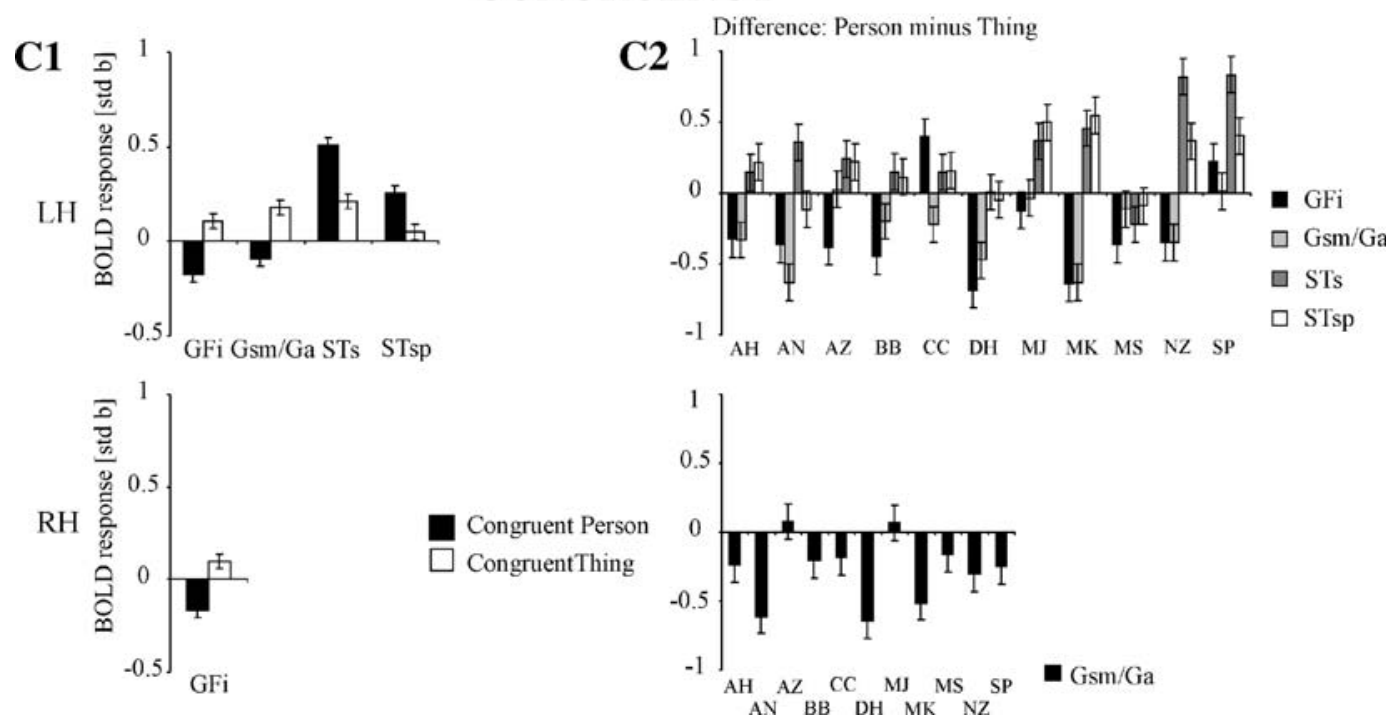

Fig. 4 - Responses to person sentences (Panel A1), thing sentences (Panel B1. Black bars represent congruent sentences and white bars represent incongruent sentences), and congruent sentences (Panel C1, black bars represent person sentences and white bars represent thing sentence.) in regions of interest as reflected in the linear-regression standardized $b$ weights ( $\beta$ estimates) averaged across subjects. Additionally the differences of $b$ weights for each individual subject are shown in A2 for person sentences, B2 for thing sentences (incongruent minus congruent), and C2 for congruent sentences (congruent person minus congruent thing). Error bars indicate the standard errors of the average $b$ weights.

Berkum et al., 2003), which, as we think, supports this idea. Alternatively, activity within GFm could be related to attention processes. The GFm activation varies between congruent and incongruent conditions, but not between the two types of congruent conditions, this area could be a member of the attention network (Corbetta and Shulman, 2002), resulting in higher activation for attention-capturing linguistic violations compared to non-violations. As both working 


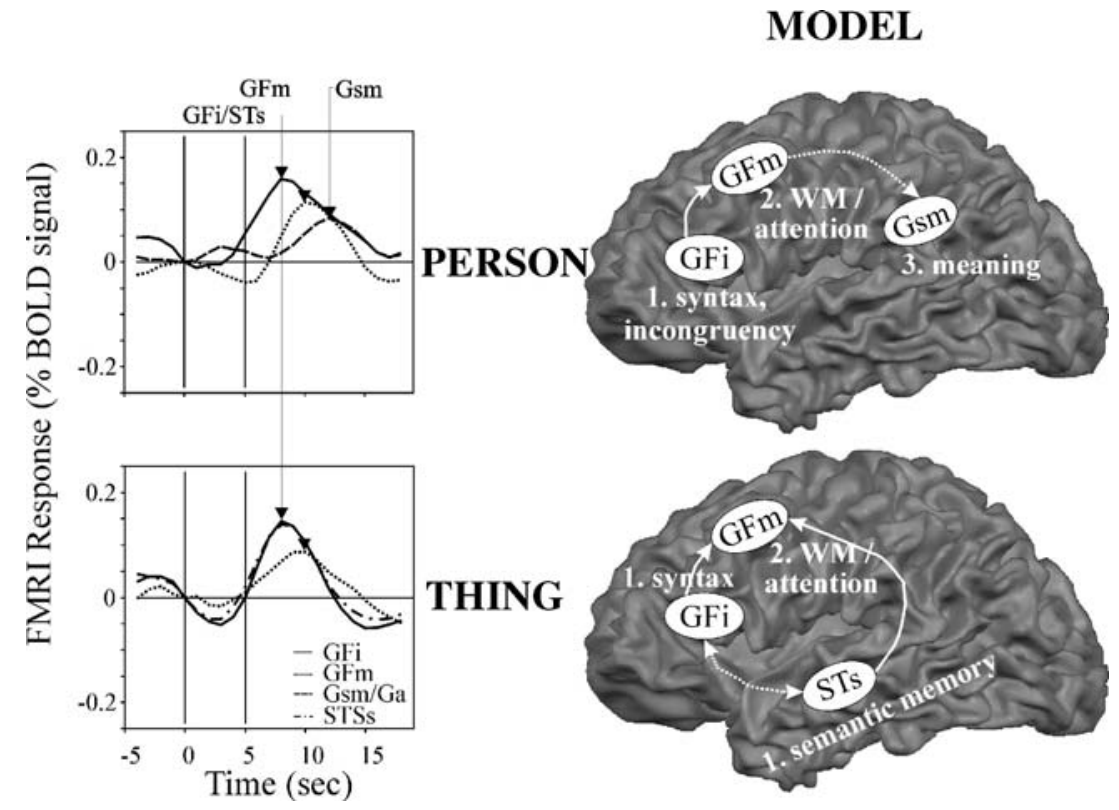

Fig. 5 - Left panel: The event-related time course of the BOLD signal change across left hemispheric regions of interest the incongruent conditions. Vertical lines display maxima in the signal change over time. Person conditions are shown in upper panel and thing condition in lower panel. Right panel: A schematic representation of proposed time courses of information access during pronoun processing. For person condition: (1) syntactic evaluation and detection of incongruency (GFi), (2) activation of working memory to receive abstract contextual information to solve incongruency (GFm) and (3) access to meaning information (Gsm/Ga). For thing condition: (1) syntactic evaluation (GFi) and access to alternatives in the semantic memory (STs), followed by (2) working memory to receive abstract contextual information to solve the incongruency (GFm).

memory and attention processes overlap within this region (Corbetta and Shulman, 2002), it is not possible to disentangle these two alternative explanations with the present experimental manipulation.

\subsection{Inferior parietal areas}

Bilateral activation of the Gsm/Ga (BA 39/40) was found for the incongruent person condition (relative to the congruent

Table 2 - ROI details for direct comparisons

\begin{tabular}{|c|c|c|c|c|c|c|c|}
\hline & \multicolumn{3}{|c|}{ Talairach } & \multirow{2}{*}{$\frac{\text { Size }}{\text { No. of voxel }}$} & \multicolumn{2}{|c|}{ Contrast } & \multirow[t]{2}{*}{$\mathrm{BA}$} \\
\hline & $x$ & $y$ & $z$ & & $t$ & $p$ & \\
\hline \multicolumn{8}{|l|}{ PERSON (i-c) } \\
\hline GFi (LH) & -40 & 17 & 21 & 85 & 5.7 & $<0.000001$ & 44 \\
\hline GFi (RH) & 49 & 12 & 17 & 655 & 6.3 & $<0.000001$ & 44 \\
\hline GFm (LH) & -43 & 3 & 53 & 146 & 4.7 & $<0.000003$ & 6 \\
\hline $\mathrm{Gsm} / \mathrm{Ga}(\mathrm{LH})$ & -47 & -49 & 38 & 1278 & 4.3 & $<0.00002$ & $39 / 40$ \\
\hline $\mathrm{Gsm} / \mathrm{Ga}(\mathrm{RH})$ & 49 & -58 & 29 & 2742 & 5.7 & $<0.000001$ & $39 / 40$ \\
\hline \multicolumn{8}{|l|}{ THING (i-c) } \\
\hline GFi (LH) & -40 & 22 & 7 & 306 & 6.4 & $<0.000001$ & 44 \\
\hline GFm (LH) & -36 & 3 & 52 & 170 & 5.3 & $<0.000001$ & 6 \\
\hline STs (LH) & -47 & -25 & -2 & 523 & 6.6 & $<0.000001$ & $21 / 38$ \\
\hline \multicolumn{8}{|c|}{ CONGRUENCY (P-T) } \\
\hline GFi (LH) & -41 & 39 & 23 & 649 & -4.9 & $<0.000002$ & 44 \\
\hline $\mathrm{Gsm} / \mathrm{Ga}(\mathrm{LH})$ & -48 & -39 & 35 & 2623 & -5.6 & $<0.000001$ & $39 / 40$ \\
\hline Gsm/Ga (RH) & 51 & -42 & 37 & 2696 & -5.6 & $<0.000001$ & $39 / 40$ \\
\hline STs (LH) & -50 & 3 & -9 & 2073 & 6.4 & $<0.000001$ & $21 / 38$ \\
\hline STs post (LH) & -49 & -53 & 19 & 346 & 4.4 & $<0.00001$ & $21 / 37$ \\
\hline
\end{tabular}


person condition) as well as for the congruent thing condition compared to the congruent person condition. Inspection of the overall morphology of the BOLD time courses suggests, however, that this area actually shows a decrease in activity for the congruent stimuli in the person condition. Interestingly, this is similar to recent findings of Kuperberg et al. (2003), who found a decrease of BOLD response in the inferior parietal regions (BA 40) for each type of sentence in their study (correct, semantically anomalous, syntactically anomalous) in relation to a low level fixation control. Importantly, the authors observed a differential deactivation. A higher amount of deactivation was observed for the pragmatically anomalous sentences and less deactivation was observed for the syntactically anomalous sentences. However, within the present study, only the congruent person pronoun were found to be deactivated in bilateral parietal regions (see Figs. 2 and 3, Panels A and C). Raichle et al. (Raichle, 1998; Raichle et al., 2001) have pointed out that parietal regions have a high resting baseline activity and therefore show deactivations in various cognitive tasks reflecting differential focused attention to the tasks. Thus, the degree of (de)activation may depend on the extent of attentional resources that are allocated in the processing of the sentences (Kuperberg et al., 2003). In fact, it is quite likely that violations attract more attention than correct sentences. In addition, things might attract more attentional resources as they are treated as more abstract than animate subjects.

\subsection{Temporal areas}

The activation of the STs for violations in thing-sentences seems to be odd at a first glance, as the STs has been associated previously with semantic processing (Kang et al., 1999; Kuperberg et al., 2000, 2003; Newman et al., 2001; Ni et al., 2000). We would like to discuss this result by briefly considering our recent ERP results (Hammer et al., 2005, see also Fig. 6) obtained with identical experimental materials. The violations were associated with a late positivity, a socalled P600 effect, in both the person and the thing condition, which was more pronounced in the former condition. This P600 effect is generally considered as reflecting the need for reanalysis (Münte et al., 1997, 1998) or integration difficulty (Friederici, 1995; Hagoort et al., 1993; Kaan et al., 2000). Importantly, we found a phasic negativity, an "N400 effect" at the word following the pronoun in incongruent sentences about things (but not about persons) compared to congruent sentences. The amplitude of the $\mathrm{N} 400$ varies as a function of the semantic relations between words (Chwilla et al., 1995; Holcomb, 1993), between words and their sentence (Kutas and Hillyard, 1980) and discourse context (van Berkum et al., 1999). The better the semantic fit between a word and its context, the smaller the amplitude of the N400, thus suggesting that the N400 amplitude can be interpreted as reflecting the processing costs of integrating a word into the overall meaning representation that is built on the basis of the preceding language input (Brown and Hagoort, 1993; Chwilla et al., 1995; Osterhout and Holcomb, 1992). We interpreted the activation pattern observed in our brain potential study as follows: In the person case, the gender violation at pronoun position is so severe (syntactically and
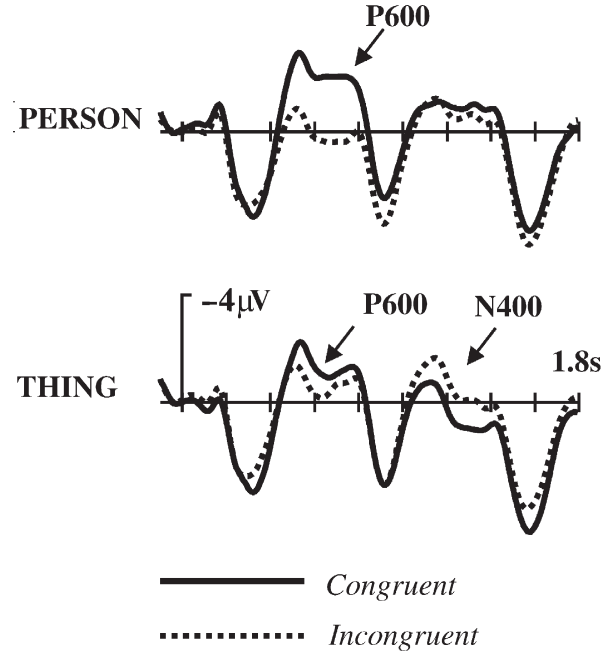

Fig. 6 - Grand average ERPs time locked to the onset of the critical pronoun at electrode P4 (negativity is plotted up and each hash mark represents 200 ms of activity, 16 participants, published in Hammer et al., 2005). Upper panel: relatively salient $\mathrm{P} 600$ effect to pronouns referring to a person as an antecedent. Lower panel: relatively small P600 ERPs to pronouns and $\mathrm{N} 400$ to word following the pronouns referring to a thing as an antecedent.

biologically bonding and resolution is signaling violation) that the reader/parser stops further attempts to integrate this mismatching pronoun, and therefore no electrophysiological signs of integration attempts were found for the word following the pronoun. In the thing case, the gender violation is purely syntactical and therefore the bonding process signals "violation", but due to the lack of any semantic information in the violation, a resolution does not take place at pronoun position. In a second ERP experiment (Hammer et al., 2005), we were able to show that the reader rather waits for a word that is related to any alternative antecedent in the discourse: If the next word matches the thing antecedent in meaning, however, the comprehension system is unable to link the pronoun to any alternative antecedent. The attempt to finally integrate fails at the position after the pronoun and leads to an N400. Importantly, generators of the N400 have been suggested to reside in anterior medial temporal area on the basis of intracranial measurements (Fernandez et al., 1998; Halgren et al., 1994a,b; Nobre et al., 1994; Nobre and McCarthy, 1995). MEG measurements again point to sources in the temporal lobe (Bonte et al., 2006; Halgren et al., 2002). Moreover, semantic violations led to activation of the left posterior STs relative to correct sentences in the study of Kuperberg et al. (2003). We therefore suggest that the STs activation in the thing condition reflects the attempts to integrate the word following the pronoun in meaning. As the time resolution of fMRI is relatively lower compared to ERPs, we suggest that the fMRI pattern reflects the average process of syntactic and contextual semantic processing (at pronoun and next word position).

The comparison of the congruent sentences revealed an increased activation for person compared to thing sentences in temporal regions. This confirms again that anterior 
temporal regions are specific for meaning integration, which is in accordance with others, see Martin and Chao (2001).

\subsection{The link to the cognitive model}

Together, the fMRI as well as our previous ERP data show pronounced differences of pronoun integration in person and thing conditions in a violation paradigm. How, then, do these differences in the neural processing of pronoun processing correspond to linguistic considerations? As mentioned in the introduction, Garrod and Sanford (1994, see also Garrod and Terras, 2000) presented a cognitive model with two stages for pronoun interpretation with (1) a low level automatic "bonding" process, and (2) a "resolution" stage. Reading a German sentence that includes a pronoun the comprehender has to go through (i) a syntactic match in terms of syntactic gender marking and possibly (ii) a semantic match in terms of biological gender marking between pronoun and antecedent. We believe that our data constitute neurophysiological evidence for this theoretical framework. Pronouns referring to persons can be matched to the antecedent by biological and syntactic information requesting more processing capacity in cases of violations (as in our experimental paradigm) indicated by the activation of five cortical areas, the bilateral GFi and Gsm/Ga and left GFm (and a large P600, see Hammer et al., 2005). The event-related BOLD signal for incongruent person conditions (Fig. 5, left upper panel) showed a time course of information availability across regions. The maximum is earliest in the left GFi, followed by GFm and then left Gsm/ $\mathrm{Ga}$. For person pronouns, and with all the caution of interpreting BOLD maxima over time, a first proposed functional time course of information access would be (see also Fig. 5, right upper panel): (1) syntactic evaluation and detection of incongruency (GFi), (2) activation of working memory/attention to receive abstract contextual information to solve incongruency (GFm) and (3) access to meaning information (Gsm/Ga).

In contrast, pronouns referring back to things are matched by pure syntactic gender information resulting in an activation of the left GFi, and GFm and a smaller P600 indicating less processing activity. For thing conditions, the time course (Fig. 5 , left lower panel) suggests nearly simultaneous activation of GFi and STs followed by GFm. Proposed time course of information access would be as follows (see also Fig. 5, right lower panel): (1) syntactic evaluation (GFi) and access to alternatives in the semantic memory (STs), followed by (2) working memory/attention to receive abstract contextual information to solve the incongruency (GFm).

We suggest that activation of the left STs within thing sentences is related to post-pronoun processing indicating difficulties with meaning integration of the word following the pronoun. For the common brain areas, we suggest that the left GFi subserves attempts at syntactic resolution, whereas the left GFm probably reflects the working memory aspects of (failing) pronoun resolution.

Thus, from a cognitive neuroscience point of view, interpreting a pronoun includes a bonding process, which is based on syntactic gender information reflected in an activation of the left GFi, and - if available - on biological/semantic gender information associated with additional activity in the right GFi and left Gsm. In case bonding has to be revised due to incongruent information, access to working memory takes place associated with an increased activity in GFm. Most interestingly, final resolution does not necessarily take place at the pronoun position but it can be delayed until unambiguous discourse information is available. This appears to be associated with temporal activation as shown for incongruent thing sentences.

Our findings illuminate the dynamic integration of syntactic and semantic/biological gender information during pronoun processing manifesting that pronoun processing is a rather flexible process that depends on the type of available gender information, and on the fact whether co-reference can be established immediately or not.

\section{Experimental procedure}

\subsection{Subjects}

For the present study, we collected fMRI images from eleven right handed, neurologically healthy, native speakers of German (mean age $28 \pm 5$ years; 7 women) while they read sentences presented in word by word fashion. Ethical approval was given by local ethical committee. All subjects gave their written consent and understanding and were paid for participation.

\subsection{Material}

The material was identical to that in the previous ERP study (Hammer et al., 2005). One-hundred twenty sentences, 60 about persons and 60 about things, were constructed. Each sentence had two clauses. The first (main) clause of each sentence described a state of a person or a thing. The person or the thing was the subject of the main clause and formed the antecedent of the pronoun following later. Care was taken to match word frequencies for persons $(295 \pm 807)$ and things $\left(155 \pm 259, t_{59}\right.$; two-tailed $\left.=1,3, p=0.2\right)$ using the CELEXdatabase (Baayen et al., 1995). The second clause was a subordinate clause introduced by the conjunction weil (because). This conjunction was followed by the critical word, a pronoun referring to the person or the thing. All sentences were then copied and the congruent pronoun was replaced by a pronoun that was incongruent in terms of biological and syntactic gender in the person condition and by syntactic gender in the thing condition but congruent with respect to case. Altogether there were four different types of

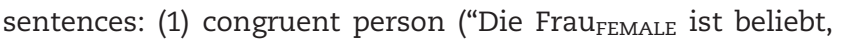

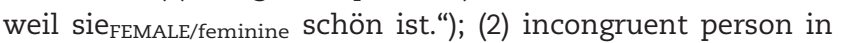
terms of biological and syntactic gender information ("Die

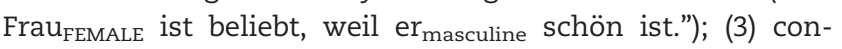
gruent thing ("Die Jacke feminine $_{\text {ist }}$ warm, weil sie feminine $_{\text {ferm }}$ gefüttert ist."); (4) and incongruent thing in terms of pure syntactic gender information ("Die Jacke feminine $_{\text {ist }}$ warm, weil er masculine gefüttert ist."). (Translation: Person-The woman is popular, because she/he is beautiful. Thing-The jacket is warm, because she/he is lined; capital letter=sex, small letter=syntactic gender.)

We used a rapid event-related design (Buckner et al., 1996; Dale and Buckner, 1997). Stimuli were presented using 
Presentation software. Sentences were presented word-byword. Each word was presented for $350 \mathrm{~ms}$ with a $300-\mathrm{ms}$ inter-stimulus interval. The main clause and the second clause were separated by a comma, which was shown with the final word of the main clause. Sentence ending words were presented with a period indicating the end of a sentence. Sentences were separated by a fixation cross in the middle of the screen, presented for a duration that varied between one to five times the duration of a volume acquisition. Subjects were instructed to read for comprehension so that they would be able to answer content-related questions.

\subsection{Data acquisition}

We measured 24 transversal slices at $3 \mathrm{~T}$ (Magnetom Trio, Siemens, Erlangen, Germany) using an echo-planar imaging sequence. The pulse-sequence parameters were as follows: acquisition matrix $64 \times 64$; field of view (FOV) $224 \mathrm{~mm}$; slice thickness $3.5 \mathrm{~mm}$; gap $1.2 \mathrm{~mm}$ (voxel size: $3.5 \times 3.5 \times 4.7 \mathrm{~mm}$ ); time to repeat (TR) $1920 \mathrm{~ms}$; time to echo (TE) $35 \mathrm{~ms}$; flip angle (FA) $75^{\circ}$; acquisition order ascending interleaved starting with slice 2. Four functional runs were acquired, with each run consisting of 375 volumes. In order to avoid a T1 saturation effect, we did not present any material during the first 10 volumes. The first four volumes were excluded from further analyses. This yielded 1484 volumes per subject.

In addition, each subject underwent a high resolution T1weighted anatomical scan using the same scanner running a three-dimensional T1-fast-low-angle shot sequence lasting $9 \mathrm{~min}$ and $50 \mathrm{~s}$ (192 slices; slice thickness $1 \mathrm{~mm}$; TR $2300 \mathrm{~ms}$; TE $3.93 \mathrm{~ms}$; FA $8^{\circ}$; FOV $256 \mathrm{~mm}$; matrix $256 \times 256$ yielding a $1 \times 1 \times 1 \mathrm{~mm}$ isotropic voxel resolution).

\subsection{Analysis}

Data analysis included preprocessing in the following order: 3D motion correction (rigid body), slice scan time correction (linear interpolation), linear trend removal and high-pass temporal filtering (cut-off frequency: $3 \mathrm{~Hz}$ ) and spatial smoothing (Gaussian Kernel: 4 mm FWHM). Functional images were coregistered to T1-weighted images acquired in the same session and transformed to Talairach space based on landmarks (anterior and posterior commissures, anterior, posterior, superior, inferior, right and left borders of the cerebrum). All preprocessing steps were performed with version 3.96 of BrainVoyager 2000 (BrainInnovation, Maastricht, The Netherlands). Surface reconstructions of grey matter in T1-weighted images (Kriegeskorte and Goebel, 2001) and subsequent statistical analyses were performed with version 1.3 of BrainVoyagerQX (Brain Innovation, The Netherlands).

We estimated percent signal change using a general linear model (GLM) for the four predictors (congruent person, incongruent person, congruent thing and incongruent thing) over the entire volume. Fixation periods served as baseline. Onset times for regressors were determined by the time, the respective sentence appeared on the screen. Duration of each event was 5.2 s. Regressors were convolved with a simple gamma function (Boynton et al., 1996). First, we applied a random-effects analysis for all predictors against baseline. To assess differences between conditions we used $t$ tests for pairwise comparisons based on a fixed effect GLM. Thresholding was controlled by false discovery rate (FDR) at $5 \%$ and $c$ $(V)=1$ (Genovese et al., 2002). This approach provides thresholds corrected for multiple comparisons. In addition, activated clusters were only accepted if more than 50 voxels were significantly activated. Reported activations are based on group statistics. In order to increase spatial correspondency in our group statistics, we performed cortex-based spherical inter-subject alignment (Fischl et al., 1999; Goebel et al., 2006). A polygon mesh of each cortical hemisphere was obtained by segmenting and tessellating the white/grey matter boundary (Kriegeskorte and Goebel, 2001). Then, cortical time courses were created by sampling the functional time series at positions corresponding to the nodes of the cortical mesh. Polygon meshes (and corresponding cortical time courses) were morphed into alignment using spherical representations of the cortical sheet (for details, see Goebel et al., 2006). For thresholding, the equivalent $t$ values to the FDR analysis were chosen ( $t>3.5)$.

\section{Acknowledgments}

The research reported in this paper was supported by a grant of the Dutch Science Foundation (NWO) to BMJ (she also published under her maiden name Schmitt) and by a grant MU1311/9-1 of the German Science Foundation (DFG) to TFM, as a bilateral co-operation project DFG/NWO.

\section{R E F E R E N C E S}

Arnold, J.E., Eisenband, J.G., Brown-Schmidt, S., Trueswell, J.C., 2000. The rapid use of gender information: evidence of the time course of pronoun resolution from eyetracking. Cognition 76, B13-B26.

Awh, E., Smith, E.E., Jonides, J., 1995. Human rehearsal processes and the frontal lobes: PET evidence. Ann. N. Y. Acad. Sci. 769, 97-117.

Baayen, R.H., Piepenbrock, R., Van Rijen, H., 1995. The Celex Lexical Database. University of Pennsylvania, Linguistic Data Consortium, Philadelphia.

Bonte, M., Parviainen, T., Hytonen, K., Salmelin, R., 2006. Time course of top-down and bottom-up influences on syllable processing in the auditory cortex. Cereb. Cortex 16, 115-123.

Bookheimer, S., 2002. Functional MRI of language: new approaches to understanding the cortical organization of semantic processing. Annu. Rev. Neurosci. 25, 151-188.

Bottini, G., Corcoran, R., Sterzi, R., Paulesu, E., Schenone, P., Scarpa, P., Frackowiak, R.S., Frith, C.D., 1994. The role of the right hemisphere in the interpretation of figurative aspects of language. A positron emission tomography activation study. Brain 117 (Pt 6), 1241-1253.

Boynton, G.M., Engel, S.A., Glover, G.H., Heeger, D.J., 1996. Linear systems analysis of functional magnetic resonance imaging in human V1. J. Neurosci. 16, 4207-4221.

Brown, C.M., Hagoort, P., 1993. The processing nature of the N400: evidence from masked priming. J. Cogn. Neurosci. 5, 34-44.

Buckner, R.L., Bandettini, P.A., O'Craven, K.M., Savoy, R.L., Petersen, S.E., Raichle, M.E., Rosen, B.R., 1996. Detection of cortical activation during averaged single trials of a cognitive task using functional magnetic resonance imaging. Proc. Natl. Acad. Sci. U. S. A. 93, 14878-14883. 
Cabeza, R., Nyberg, L., 2000. Imaging cognition II: An empirical review of 275 PET and fMRI studies. J. Cogn. Neurosci. 12, 1-47.

Caplan, R., Dapretto, M., 2001. Making sense during conversation: an fMRI study. NeuroReport 12, 3625-3632.

Caplan, D., Alpert, N., Waters, G., 1998. Effects of syntactic structure and propositional number on patterns of regional cerebral blood flow. J. Cogn. Neurosci. 10, 541-552.

Chwilla, D.J., Brown, C.M., Hagoort, P., 1995. The N400 as a function of the level of processing. Psychophysiology 32, 274-285.

Corbetta, M., Shulman, G.L., 2002. Control of goal-directed and stimulus-driven attention in the brain. Nat. Rev., Neurosci. 3, 201-215.

Coulson, S., King, J.W., Kutas, M., 1998. ERPs and domain specifity: beating a straw horse. Lang. Cogn. Processes 13, 653-672.

Dale, A.M., Buckner, R.L., 1997. Selective averaging of rapidly presented individual trials using fMRI. Hum. Brain Mapp. 5, 329-340.

Fernandez, T., Harmony, T., Silva, J., Galan, L., Diaz-Comas, L., Bosch, J., Rodriguez, M., Fernandez-Bouzas, A., Yanez, G., Otero, G., Marosi, E., 1998. Relationship of specific EEG frequencies at specific brain areas with performance. NeuroReport 9, 3681-3687.

Fiebach, C.J., Schlesewsky, M., Friederici, A.D., 2001. Syntactic working memory and the establishment of filler-gap dependencies: insights from ERPs and fMRI. J. Psycholinguist. Res. 30, 321-338.

Fischl, B., Sereno, M.I., Tootell, R.B., Dale, A.M., 1999. High-resolution intersubject averaging and a coordinate system for the cortical surface. Hum. Brain Mapp. 8, 272-284.

Friederici, A.D., 1995. The time course of syntactic activation during language processing: a model based on neuropsychological and neurophysiological data. Brain Lang. 50, 259-281.

Friederici, A.D., Ruschemeyer, S.A., Hahne, A., Fiebach, C.J., 2003. The role of left inferior frontal and superior temporal cortex in sentence comprehension: localizing syntactic and semantic processes. Cereb. Cortex 13, 170-177.

Garnham, A., Oakhill, J., Ehrlich, M.F., Carreiras, M., 1995. Representations and the processes in the interpretation of pronouns: new evidence from Spanish and Frensh. J. Mem. Lang. 34, 41-62.

Garrod, S.C., Sanford, A.J., 1994. Resolving sentences in a discourse context. In: Gernsbacher, M.A. (Ed.), Handbook of Psycholinguistics. Academic Press, New York, pp. 675-698.

Garrod, S.C., Terras, M., 2000. The contribution of lexical and situational knowledge to resolving discourse roles: bonding and resolution. J. Mem. Lang. 42, 526-544.

Genovese, C.R., Lazar, N.A., Nichols, T., 2002. Thresholding of statistical maps in functional neuroimaging using the false discovery rate. NeuroImage 15, 870-878.

Gernsbacher, M.A., Shroyer, S., 1989. The cataphoric use of the indefinite this in spoken narratives. Mem. Cogn. 17, 536-540.

Gibson, E., 1998. Linguistic complexity: locality of syntactic dependencies. Cognition 68, 1-76.

Goebel, R., Esposito, F., Formisano, E., 2006. Analysis of functional image analysis contest (FIAC) data with BrainVoyager QX: from single-subject to cortically aligned group general linear model analysis and self-organizing group independent component analsis. Hum. Brain Mapp. 27, 392-401.

Goel, V., Buchel, C., Frith, C., Dolan, R.J., 2000. Dissociation of mechanisms underlying syllogistic reasoning. NeuroImage 12, 504-514.

Grewe, T., Bornkessel, I., Zysset, S., Wiese, R., von Cramon, D.Y., Schlesewsky, M., 2005. The emergence of the unmarked: a new perspective on the language-specific function of Broca's area. Hum. Brain Mapp. 26, 178-190.

Hagoort, P., Brown, C.M., Groothusen, J., 1993. The syntactic positive shift (SPS) as an ERP measure of syntactic processing. Lang. Cogn. Processes 8, 439-483.
Hagoort, P., Brown, C.M., Osterhout, L., 1999. The neurocognition of syntactic processing. In: Brown, C.M., Hagoort, P. (Eds.), The Neurocognition of Language. University Press, Oxford, pp. 273-316.

Hagoort, P., Hald, L., Bastiaansen, M., Petersson, K.M., 2004. Integration of word meaning and world knowledge in language comprehension. Science 304, 438-441.

Halgren, E., Baudena, P., Heit, G., Clarke, J.M., Marinkovic, K., Chauvel, P., Clarke, M., 1994a. Spatio-temporal stages in face and word processing. 2. Depth-recorded potentials in the human frontal and Rolandic cortices. J. Physiol. (Paris) 88, 51-80.

Halgren, E., Baudena, P., Heit, G., Clarke, J.M., Marinkovic, K., Clarke, M., 1994b. Spatio-temporal stages in face and word processing. 1. Depth-recorded potentials in the human occipital, temporal and parietal lobes [corrected]. J. Physiol. (Paris) 88, 1-50.

Halgren, E., Dhond, R.P., Christensen, N., Van Petten, C., Marinkovic, K., Lewine, J.D., Dale, A.M., 2002. N400-like magnetoencephalography responses modulated by semantic context, word frequency, and lexical class in sentences. NeuroImage 17, 1101-1116.

Hammer, A., Jansma, B.M., Lamers, M., Münte, T.F., 2005 Pronominal reference in sentences about persons or things: an electrophysiological approach. J. Cogn. Neurosci. 17, 227-239.

Holcomb, P.J., 1993. Semantic priming and stimulus degradation: implications for the role of the N400 in language processing. Psychophysiology 30, 47-61.

Indefrey, P., Hagoort, P., Herzog, H., Seitz, R.J., Brown, C.M., 2001. Syntactic processing in left prefrontal cortex is independent of lexical meaning. NeuroImage 14, 546-555.

Jonides, J., Smith, E.E., Koeppe, R.A., Awh, E., Minoshima, S., Mintun, M.A., 1993. Spatial working memory in humans as revealed by PET. Nature 363, 623-625.

Jonides, J., Schumacher, E.H., Smith, E.E., Koeppe, R.A., Awh, E., Reuter Lorenz, P.A., Marshuetz, C., Willis, C.R., 1998. The role of parietal cortex in verbal working memory. J. Neurosci. 18, 5026-5034.

Kaan, E., Harris, A., Gibson, E., Holcomb, P.J., 2000. The P600 as an index of syntactic integration difficulty. Lang. Cogn. Processes 15, 159-201.

Kang, A.M., Constable, R.T., Gore, J.C., Avrutin, S., 1999. An event-related fMRI study of implicit phrase-level syntactic and semantic processing. NeuroImage 10, 555-561.

Kiehl, K.A., Laurens, K.R., Liddle, P.F., 2002. Reading anomalous sentences: an event-related fMRI study of semantic processing. NeuroImage 17, 842-850.

Kolk, H.H., Chwilla, D.J., van Herten, M., Oor, P.J., 2003. Structure and limited capacity in verbal working memory: a study with event-related potentials. Brain Lang. 85, 1-36.

Kriegeskorte, N., Goebel, R., 2001. An efficient algorithm for topologically correct segmentation of the cortical sheet in anatomical mr volumes. NeuroImage 14, 329-346.

Kuperberg, G.R., McGuire, P.K., Bullmore, E.T., Brammer, M.J., Rabe Hesketh, S., Wright, I.C., Lythgoe, D.J., Williams, S.C., David, A.S., 2000. Common and distinct neural substrates for pragmatic, semantic, and syntactic processing of spoken sentences: an fMRI study. J. Cogn. Neurosci. 12, 321-341.

Kuperberg, G.R., Holcomb, P.J., Sitnikova, T., Greve, D., Dale, A.M., Caplan, D., 2003. Distinct patterns of neural modulation during the processing of conceptual and syntactic anomalies. J. Cogn. Neurosci. 15, 272-293.

Kutas, M., Hillyard, S.A., 1980. Reading senseless sentences: brain potentials reflect semantic incongruity. Science 207, 203-205.

Kutas, M., Federmeier, K.D., Coulson, S., King, J.W., Münte, T.F., 2000. Language, In: Cacioppo, J.T., Tassinary, G., Berntson, G.G. (Eds.), Handbook of Psychophysiology, 2nd ed. Cambridge Univ. Press, New York, pp. 576-601. 
LaBar, K.S., Gitelman, D.R., Parrish, T.B., Mesulam, M., 1999. Neuroanatomic overlap of working memory and spatial attention networks: a functional MRI comparison within subjects. NeuroImage 10, 695-704.

Martin, A., Chao, L.L., 2001. Semantic memory and the brain: structure and processes. Curr. Opin. Neurobiol. 11, 194-201.

Mashal, N., Faust, M., Hendler, T., 2005. The role of the right hemisphere in processing nonsalient metaphorical meanings: application of principal components analysis to fMRI data. Neuropsychologia 43, 2084-2100.

Münte, T.F., Matzke, M., Johannes, S., 1997. Brain activity associated with syntactic incongruencies in words and pseudo-words. J. Cogn. Neurosci. 9, 318-329.

Münte, T.F., Heinze, H.J., Matzke, M., Wieringa, B.M., Johannes, S., 1998. Brain potentials and syntactic violations revisited: no evidence for specificity of the syntactic positive shift. Neuropsychologia 36, 217-226.

Newman, A.J., Pancheva, R., Ozawa, K., Neville, H.J., Ullman, M.T., 2001. An event-related fMRI study of syntactic and semantic violations. J. Psycholinguist. Res. 30, 339-364.

Ni, W., Constable, R.T., Mencl, W.E., Pugh, K.R., Fulbright, R.K., Shaywitz, S.E., Shaywitz, B.A., Gore, J.C., Shankweiler, D., 2000. An event-related neuroimaging study distinguishing form and content in sentence processing. J. Cogn. Neurosci. 12, 120-133.

Nobre, A.C., McCarthy, G., 1995. Language-related field potentials in the anterior-medial temporal lobe: II. Effects of word type and semantic priming. J. Neurosci. 15, 1090-1098.

Nobre, A.C., Allison, T., McCarthy, G., 1994. Word recognition in the human inferior temporal lobe. Nature 372, 260-263.

Osterhout, L., Holcomb, P.J., 1992. Event-related brain potentials elicited by syntactic anomaly. J. Mem. Lang. 34, 785-806.

Osterhout, L., Bersick, M., McLaughlin, J., 1997. Brain potentials reflect violations of gender stereotypes. Mem. Cogn. 25, 273-285.
Raichle, M.E., 1998. The neural correlates of consciousness: an analysis of cognitive skill learning. Philos. Trans. R Soc. Lond., B Biol. Sci. 353, 1889-1901.

Raichle, M.E., MacLeod, A.M., Snyder, A.Z., Powers, W.J., Gusnard, D.A., Shulman, G.L., 2001. A default mode of brain function. Proc. Natl. Acad. Sci. U. S. A. 98, 676-682.

Röder, B., Stock, O., Neville, H., Bien, S., Rosler, F., 2002. Brain activation modulated by the comprehension of normal and pseudo-word sentences of different processing demands: a functional magnetic resonance imaging study. NeuroImage 15, 1003-1014.

Schmitt, B.M., Lamers, M., Münte, T.F., 2002. Electrophysiological estimates of biological and syntactic gender violation during pronoun processing. Brain Res. Cogn. Brain Res. 14, 333-346.

Schumacher, E.H., Lauber, E., Awh, E., Jonides, J., Smith, E.E., Koeppe, R.A., 1996. PET evidence for an amodal verbal working memory system. NeuroImage 3, 79-88.

Stromswold, K., Caplan, D., Alpert, N., Rauch, S., 1996. Localization of syntactic comprehension by positron emission tomography. Brain Lang. 52, 452-473.

Tomaiuolo, F., MacDonald, J.D., Caramanos, Z., Posner, G., Chiavaras, M., Evans, A.C., Petrides, M., 1999. Morphology, morphometry and probability mapping of the pars opercularis of the inferior frontal gyrus: an in vivo MRI analysis. Eur. J. Neurosci. 11, 3033-3046.

van Berkum, J.J., Hagoort, P., Brown, C.M., 1999. Semantic integration in sentences and discourse: evidence from the N400. J. Cogn. Neurosci. 11, 657-671.

van Berkum, J.J., Brown, C.M., Hagoort, P., Zwitserlood, P., 2003. Event-related brain potentials reflect discourse-referential ambiguity in spoken language comprehension. Psychophysiology 40, 235-248.

van Herten, M., Kolk, H.H., Chwilla, D.J., 2005. An ERP study of P600 effects elicited by semantic anomalies. Brain Res. Cogn. Brain Res. 22, 241-255. 